\title{
INDÚSTRIA CINEMATOGRÁFICA: CARMEN MIRANDA NO MUNDO DA ARTE E DO CONSUMO
}

\author{
ELIANE MEIRE SOARES RASLAN \\ Universidade do Estado de Minas Gerais - UEMG \\ Belo Horizonte, Minas Gerais, Brasil \\ E-mail: elianest2002@yahoo.com.br
}


INDÚSTRIA CINEMATOGRÁFICA: CARMEN MIRANDA NO MUNDO DA ARTE E DO CONSUMO

Resumo: Pensando no cinema arte, que existiu ou não, consideramos que ele nunca deixou de ser comercializado. As ideias do cineasta François Truffaut sobre o cinema na sua expressão e sentido nos permitem exemplificar a comercialização dos filmes com Carmen Miranda, figura que colaborou para alavancar a indústria cinematográfica com alto índice de aceitação dos filmes norte-americanos em diversos países. Analisamos as atitudes e consequências dos cineastas buscando a preferência do espectador e do consumo, sobretudo, tratando a questão da estética.

Palavras-chave: Arte; Carmen Miranda; indústria cinematográfica; consumo.

FILM INDUSTRY: CARMEN MIRANDA IN THE WORLD OF THE ART AND CONSUMPTION

Abstract: Thinking in cinema art, which existe dor not, consider that he never ceased to be traded. The ideas of filmmaker François Truffaut about the film in its expression and direction allow us to exemplify the marketing of movies with Carmen Miranda, who collaborated figure to boost film industry with high acceptance of U.S. films in various countries. We analyze the attitudes and consequences of filmmakers seeking viewer preference and consumption, particularly, treating the question of aesthetics.

Keywords: Art; Carmen Miranda; film industry; consumption.

\section{INDÚSTRIA CINEMATOGRÁFICA: CARMEN MIRANDA EN EL MUNDO DEL ARTE Y EL CONSUMO}

Resumen: Pensando en el arte del cine, que existió o no, tenga en cuenta que él nunca dejó de ser comercializados. Las ideas del cineasta François Truffaut en el cine en su expresión y la dirección nos permiten ejemplificar la comercialización de las películas con Carmen Miranda, figura la cooperación para impulsar la industria del cine con un alto nivel de aceptación de las películas americanas en diferentes países. Analizadas las actitudes y las consecuencias de los cineastas que buscan la elección del espectador y el consumo, sobre todo por el tratamiento de la cuestión de la estética.

Palabras clave: Arte; Carmen Miranda; industria del cine; consumo. 


\section{INTRODUÇÃO}

O cinema passou a ter sua arte a ofício da estética, ou mesmo, podemos dizer, aserviço da indústria de entretenimento. As técnicas no cinema distanciam a incorporação do personagem interpretado pelo ator. Existe um aparato de técnicas de reprodução e de manipulação. Carmen Miranda soube representar e transcender seu personagem e ganhou sucesso internacional sem dispor desses recursos tecnológicos. Em certo momento temos o impacto dos filmes na sua visão estética e em outro temos a visão no mercado consumidor.

Nesse período, o mercado brasileiro foi invadido pelos Estados Unidos que afastou muitos países concorrentes como França e Itália. Nossa aceitação, ou mesmo, a imposição dos produtos americanos modificou nossos hábitos. O cinema foi um dos meios de comunicação de maior força para atrair a simpatia dos brasileiros pelos produtos americanos. Mas, a cantora e atriz Carmen Miranda também soube aproveitar os interesses da chamada política de Boa Vizinhança criada pelos estadunidenses para os países latino-americanos. Assim, as primeiras formas de globalização surgiram com o cinema hollywoodiano.

\section{A ARTE DE SE COMERCIALIZAR CINEMA COM CARMEN MIRANDA: TÉCNICAS DE ATRAÇÃO A PARTIR DE FRANÇOIS TRUFFAUT}

O mecanismo ocidental, que impulsionou a globalização, gerou transformações de conceitos culturais mundialmente. A identidade de cada país passou a ser discutida como meio cultural e comercial. Por mais que a globalização tenha sido impulsionada por interesses econômicos e políticos não temos como deixar de relacionar as causas a efeitos históricos. Nesse sentido, buscar o cinema na arte e no consumo, na visão de François Truffaut, é uma alternativa apropriada para tratarmos dos valores estéticos e da comercialização da imagem de Carmen Miranda no cinema. Isso é o que faremos agora.

Com o início da Segunda Guerra Mundial houve grande influência do cinema norte-americano aos cineastas franceses. Truffaut (1989) expõe sua opinião sobre os filmes americanos, de acordo com o autor, era grande a expectativa europeia quanto ao seu lançamento a partir de 1945 nos EUA. Ele comparou produções cinematográficas de diretores entre as décadas 
de 1940 a 1950 com seus filmes de 1975. Não era o caso de não existir no mercado "diretores inteligentes, mas eles eram levados a mascarar sua personalidade a fim de preservar a universalidade dos filmes que realizavam." (p.18). Não existia a preocupação de se confirmarem na tela, pois atrás das câmeras mostravam sua inteligência. Não há como ser preciso ao conceituar o autor. $O$ "sonho" é algo que carece ser materializado para que seja possível o autor de alguma forma demonstrar sua sensibilidade.

Truffaut (1989) considera necessário sentir, ter gosto e noção do que se faz. Nos anos 50 existia muito mais o imaginativo ou mesmo o sonho no conteúdo dos filmes. Por isso, sempre procurou ser fiel à obra e foi um dos maiores críticos nessa época quanto à produção literária no cinema. Tratou de realismo psicológico, o que não era possível adaptar do livro para a filmagem, cenas que acabavam sendo inventadas pelo cineasta. Uma característica curiosa de suas pesquisas foi ter comparado a direção de um filme à escrita de um livro. As críticas em torno de seu trabalho estavam centradas no fracasso de bilheteria.

No entanto, ao cineasta o que mais importava era que a personalidade do filme revelasse o seu autor, sendo necessário ir além do sentido comum, empregar a verdadeira arte ultrapassando os sentimentos. Mesmo que fosse preciso buscar o simbólico da obra de arte para se expressar, o cineasta tenta juntar-se aos demais expressando o que existe dentro dele. Se pensarmos no sentido de autor, quanto à ideia de Truffaut, podemos afirmar que não está na certeza absoluta, e sim em uma crença. A arte do cinema é um gosto pessoal. Mas, ele, o autor, não será autônomo, pois estará ligado a um lugar e a um tempo.

Nesse sentido, a história serve de inspiração. Existe percepção do cineasta entre coisas e objetos. A questão do estilo influencia na linguagem, algo que vem do universo cinematográfico. Truffaut filmou em estúdios com cores, mas tinha uma preferência pela filmagem ao natural em preto e branco, como podemos notar no seu filme de 1960 Atirem no pianista (TirezsurlePianiste). Dos seus 25 filmes produzidos nem todos foram rodados ao público francês, que o considerava representante do "espírito" do modo de ser da população francesa. Truffaut (1989) assegura ser necessário ousadia para se fazer um filme; afirma faltar ousadia nos filmes franceses.

Truffaut $^{1}$ (1990) fala do primeiro filme que lembra ter tido contato, $O$

1 François Roland Truffaut (1932-1984) cineasta, roteirista, produtor, ator e conhecido pela 
paraíso perdido (ParadisPerdu), de Abel Gance de 1939, que devido às coincidências históricas emocionava. Os cinemas ficavam cheios de soldados licenciados que estavam voltando ou partindo da guerra. $O$ enredo retrata a Guerra de 1914 e foi um sucesso de bilheteria na França. Truffautgarante ter gostado mais dos filmes franceses e que pôde assistir a eles durante a guerra. Filmes como O Corvo (Le Corbeau) e Os visitantes da Noite (LesVisiteurs), comenta tê-los revisto várias vezes.

O Roteirista considera ainda ser possível produzir filmes para distrair e esquecer a tristeza que a guerra causava. Logo, podemos buscar filmes que tiveram alto destaque nesse período, tanto pelo consumo quanto por ter virado marco histórico, principalmente no Brasil e EUA, como, por exemplo, os filmes musicais de comédia que Carmen Miranda participou.

Da carreira em Hollywood, o sucesso veio com o seu primeiro filme norte americano Serenata tropical (DownArgentine Way) de 1940. Quem assistiu à versão recentemente restaurada no Brasil não consegue perceber que o filme tem 70 anos. Podemos pensar ser um filme de época, por causa das roupas, cortes e pentidados de cabelos, mas não produzido há tanto tempo. A música SouthAmerican Way é cantada por Carmen Miranda em inglês no início do filme, depois em outras cenas ela canta Mamãe eu quero e Bambu, bambu. Em 1941, participou do filme Uma noite no Rio (Thatnight in Rio).

As fotografias, em cores, impressionam. O que também surpreende é o fascínio que ela despertava no público; todos cantavam suas canções como se estivessem em um show. Assim, seus filmes contribuíram para comercialização e serviam de entretenimento para esquecer o momento dos conflitos entre os países. O filme Uma noite no Rio mostra o poder do comércio americano. Nele há o destaque da latina Carmen Miranda, no entanto colocam um barão brasileiro que não fala português no intuito de manter o domínio da língua inglesa. Os norte-americanos sentem-se avançando na exportação de seus produtos e preferem esquecer-se da violência da guerra.

Ambos os filmesforam originados nos EUA. De gênero musical, foram dirigidos por Irving Cummings². Já o filme Aconteceu em Havana (Week-End in Havana) também lançado em 1941 foi produzido por Walter Lang; é de um colori-

influência crítica do cinema. Foi um dos fundadores da Nouvelle Vague Francesa e trabaIhou em mais de 25 filmes. Gosta de melodramas e relata seus filmes como conto de fadas, fundamentado na numeração.(FRANCOIS TRUFFAUT, 2011).

2Fonte: Los Angeles Times - The awards and industry insider. <Disponível em: http://projects.latimes.com/hollywood/star-walk/irving-cummings/> Acesso em: 07 dezembro de 2012. 
do natural que parece ser reproduzido com montagens. O colorido destacado pela decoração de fundo de palco denota a referência brasileira da atriz.

Analisamos o filme Serenata tropical, que foi pensado desde a produção como técnica de atração e comercialização. Segundo Truffaut, este foi um filme para "distrair" a tensão das lutas armadas. O longa-metragem procura mostrar o modo de vida dos argentinos, tanto que o personagem Diego Quintana (Henry Stephenson) vive um criador de cavalos na Argentina. Nesta produção, colocaram Carmen Miranda como uma figura associada ao sexo, tendo a sensualidade transpassada por meio da extravagância das roupas. Quando começava a dançar e cantar existia destaque para os gestos. A dança configurava-se sensual para os padrões da época.
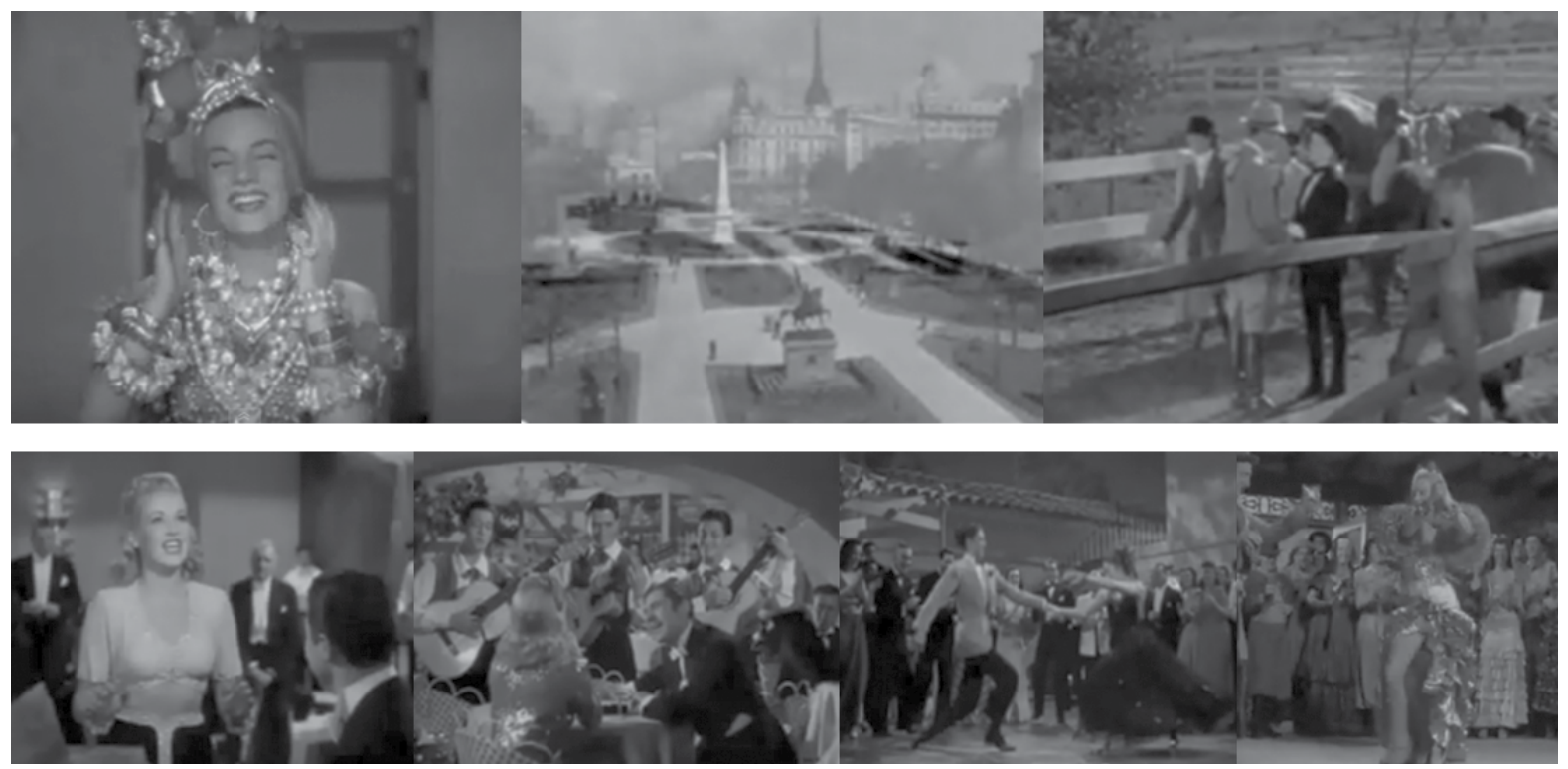

Figura 01-07 - Fotos tiradas do longa-metragem Serenata Tropical(Down Argentine Way). Fonte:Serenata Tropical. Direção: Irving Cummings. EUA,20th Century Fox, 1940.1 DVD (89 min), color.Comédia Musical. Título original Down Way Argentina.

Como podemos observar nas gravuras, o filme inicia com Carmen Miranda (fig.01) cantando e dançando no palco, representando a cultura latino-americana. A atriz aparece outras vezes, sempre vestida de baiana. No decorrer do filme, aparecem imagens (fig.02) de pontos turísticos da Argentina, como o Obelisco em mármore erguido naPraçada República. Em seguida partem para um hipódromo, onde a americana Charlotte Greenwood (fig. 03-07) no papel de Binnie Crawford consegue a vitória na corrida de cavalos. Na próxima cena há uma comemoração, a atriz (fig. 04) canta com o acompanhamento, personagem argentino - que nesta cena toca piano -, e outros amigos. 
O filme segue com mais comemorações. Binnie ganha destaque pela beleza. A personagem sempre bem vestida, em situações ligadas ao luxo, conotativamente pode ser entendida como a superioridade cultural branca e norte-americana. A atriz, que na vida real é conhecida em vários países e admirada pelos americanos, apresenta, nesse filme, Carmen Miranda aos EUA. É como se ela estivesse apadrinhando o início da carreira da brasileira. Um modo de aumentar as chances de aceitação frente ao público americano.

Os argentinos fazem os papéis mais desfavoráveis, exceto no caso do personagem Diego que contracena com Binnie. Nesse momento os EUA reforçam a aceitação do país latino. O filme mostra os EUA no controle e que os americanos não têm preconceitos, porque sua atriz faz par romântico com um ator sul-americano. Durante todo o filme mostraram a dança e a música dos argentinos (fig. 05 e 07), porém na apresentação de tango os dançarinos (fig. 06 e 07) são vulgares e misturam ritmos diferentes à dança típica da cultura argentina.

No tango realmente há vestimentas sensuais como foi mostrado no filme, contudo com elegância. Por outro lado, podemos levar em consideração a pouca experiência dos americanos referente à cultura latina e o fato dos atores norte-americanos não conhecerem os passos de dança do tango. Nesse sentido, pode ter havido falta de experiência ou de tempo da produção. Por outro lado, também pode ter ocorrido exagero na interpretação o que nos induz a entender que a intenção era o destaque para os americanos, que são mostrados sempre com beleza e sedução com forte descrição nas falas e nas roupas. Já os personagens brasileiros e os argentinos eram representados com vulgaridade. O Brasil, como foi representado por uma brasileira, conseguiu aproximar a atuação da realidade nacional, mostrando o ritmo das raízes brasileiras, mesmo porque Carmen Miranda tinha suas exigências de contrato na vida real.

Carmen Miranda dançava de forma sensual, sem exageros. Essa voluptuosidade geralmente despertava ciúmes nos outros personagens femininos. Por um lado, as roupas e os apetrechos a vulgarizavam, contrapondo-a a elegância da figura feminina americana. Por outro lado, a atriz atuava somente em lugares nobres onde os americanos saiam para comemorar vitórias ou se divertirem. Nesse caso, ela incluía-se na sociedade americana, representando a aceitação do latino na cultura estrangeira. Lembrando que essa aceitação estava relacionada a sua cor, uma vez que já comentamos que a população de modo geral era preconceituosa quanto a cor de pele - 
tanto o público norte como o latino-americano. Mas, não podemos deixar de relatar que a atriz foi um personagem criado visando à descontração, o intuito era fazer o público rir. Assim, o exagero, que em alguns momentos ridicularizava o Brasil, justificava-se.

Seus filmes eram comédias musicais, o elemento risível aparecia por meio da extravagência dos figurinos. Quanto a Serenata Tropical, podemos afirmar que foi o típico filme de comédia hollywoodiano feito para se ganhar dinheiro. Os filmes em que Carmen Miranda atuou fizeram um sucesso inesperado. Com falhas e acertos, buscaram melhorar o modo de expressar a cultura dos países latinos, alavancaram, com isso, a indústria cinematográfica e conseguiram outros negócios comerciais com vários países.

Voltemos ao crítico e cineasta Truffaut (1990), que pensa ser sempre possível melhorar um filme. No caso de Atirem no pianista, segundo ele, o filme poderia ter sido feito sem flashback; de modo a narrar a história linearmente, o que tornaria difícil quanto ao próprio trabalho alcançar a objetividade. Talvez o filme não tenha tido sucesso como Os incompreendidos pelo seu exagero em buscar fidelidade ao livro.

No filme de 1962, Uma mulher para dois (Jules et Jim), há uma canção que o tom revela a chave do filme, a Le Tourbillon de I avie. O longa, sob a tensão da Primeira Guerra Mundial, mostra o conflito de dois homens apaixonados pela mesma mulher. Os personagens são muito puros, porém insatisfeitos; o filme é moral e com cenas inocentes, retratando a polêmica do triângulo amoroso de modo muito sutil. Truffaut (1990) comenta que houve um grande lapso marcado com o nascimento dos filhos dos personagens, mas que também foi cortado pela guerra e morte, marcando uma existência inteira, o que permitiu transmitir uma noção melhor ao espectador. Tinha as raízes mais profundas do que o próprio cineasta Truffaut poderia imaginar, afirma o próprio autor.

Hoje percebemos a ligação profunda do filme com sua própria identidade. O filme leva o espectador a sonhar com o amor definitivo, todos sofrem com o aspecto provisório do amor. Truffaut (1990) afirma que em filmes como A noiva estava de preto (La MariéeÉtait em Noir), de 1967, foi uma ideia que teve de adaptar o romancelrishque concorreu determinada época com a Série noire. Havia histórias que se assemelhavam ao pesadelo ao invés de um meio social bem definido com gangsters. A ideia de Irishera de fatalidade e amor proibido com histórias pavorosas.

$O$ roteirista acredita que sempre tenta fazer um produto francês, par- 
tindo de um produto inglês ou americano. "Tenho certeza de que os americanos não teriam feito A noiva estava de preto com o mesmo espírito, mas tentariam tornar a noiva mais simpática. $O$ estilo europeu costuma arredondar os ângulos, ao invés de reforçar o drama, é a tentativa constante de atenuá-lo" (p.183), diz Truffaut (1990). No enredo do longa citado, uma muIher - movida pelo desejo de vingança porque teve seu parceiro morto logo após a cerimônia do casamento -decide matar os homens que estavam envolvidos no assassinato do marido. Embalada pela trilha sonora de Bernard Hermmann, a história é marcada por uma atmosfera de suspense e densa construção psicológica.

Para Truffaut (1990), a música faz toda diferença, o jazz que quase não se adequou aos filmes pode virar uma linda melodia no roubo da máquina de escrever e a imagem duplica seu tempo de duração. Caso o filme seja todo decorativo, a música diante da imagem irá combinar, como no filme Aconteceu em Veneza (Sait-on jamais)de 1957. A música deve reforçar e ajudar a imagem. E não ilustrar a imagem. Truffaut (1990) considera Georges Deleuze o mais “cinéfilo" entre os músicos, por buscar a perfeição na arquitetura de um filme.

O produtor ainda acredita que se necessita de uma linha que direcione de forma sólida; preocupa-se muito com a coerência do filme. Afirma que Jean-Luc coloca a coerência do conjunto no final, segue muito dos ímpetos do momento, correndo o risco de uma lacuna existir no meio da história. Depende pouco do roteiro como é o caso dos italianos. Truffaut diz aproximarse de Hitchcock por prender-se muito ao movimento ascendente e aproximar-se do espetáculo. Acredita que está associado à direção e a vocação do espetáculo, como Fellini e Welles.

Considera também que, muitas vezes, falta o essencial nos filmes: o cineasta. De forma geral, tentam imitar Godard, tornando-se insuportáveis. Imitam os jogos de palavras, mas não conseguem imitar a crueldade. Truffaut fala do seu filme o Garoto selvagem (L'enfantsauvage), de 1970, que para conseguir perceber se o garoto tinha consciência moral - se conseguiria se comunicar - era preciso realizar um roteiro com Jean Gruault que fizesse "funcionar" e depois o dividia em duas partes. As variedades constituíam a primeira parte, a floresta, o intuito de surdos-mudos, a captura, a curiosidade dos parisienses, quando o garoto tem como responsável o Itard. A reeducação era a segunda parte, os exercícios, reduzindo a "variedade". Truffaut (1990) percebeu que somente na relação entre Victor, o garoto e 
Itard, quem o retirou do meio selvagem, poderia realmente começar o filme. Considerava positiva a fuga e o retorno do garoto de forma voluntária, apresentando acontecimentos autênticos. Já em seu filme de 1970, Domicílio Conjugal (Domícilo Conjugal), feito como certo tipo de comédia americana, tem impressão de ter denegrido Antoine Doinel. Exemplo dessa visão seria o filme Um só pecado, com o personagem Pierre Lachenay.

O cineasta Turffaut (1990) nunca realizou nenhum projeto cinematográfico com regra absoluta, encomendado ou por motivo publicitário. Seus filmes sempre foram escolhidos por vontade própria. O filme de 1973, A noite Americana (La NuitAmericaine), foi como um documentário. "Com o surgimento do cinema falado houve certa perda de qualidade, mas a introdução do som não permitiu que um filme como King Kong fosse muito bonito em sua concepção e bastante ambicioso visualmente" (p.427), que são combinações diferentes.

Truffaut (1990) assegura que nos filmes americanos "tudo o que Henry Fonda ou Montgomery Clift fazem, nós acreditamos. Ao sair de um filme com Humphrey Bogart, não conseguimos dizer que o filme é ruim" (p.319). A produção foi tão bem realizada que mesmo que tenha sido ruim não percebemos seus pontos fracos. Considera-o tradicional; não gosta dos filmes que proporcionam nas pessoas um olhar de surpresa no momento do desfecho.

Agora busquemos como exemplo os filmes de Carmen Miranda, norteando a discussão a partir das teorias de François Truffaut. Não fazendo juízos de valor, sabemos que muitas vezes os interesses são voltados para a comercialização. Dessa forma, arte e estética fazem com que o plano da beleza, ilusão e conquista seja algo que muitas vezes deixamos de trabalhar para atender a demanda de quem paga para produzir o filme.

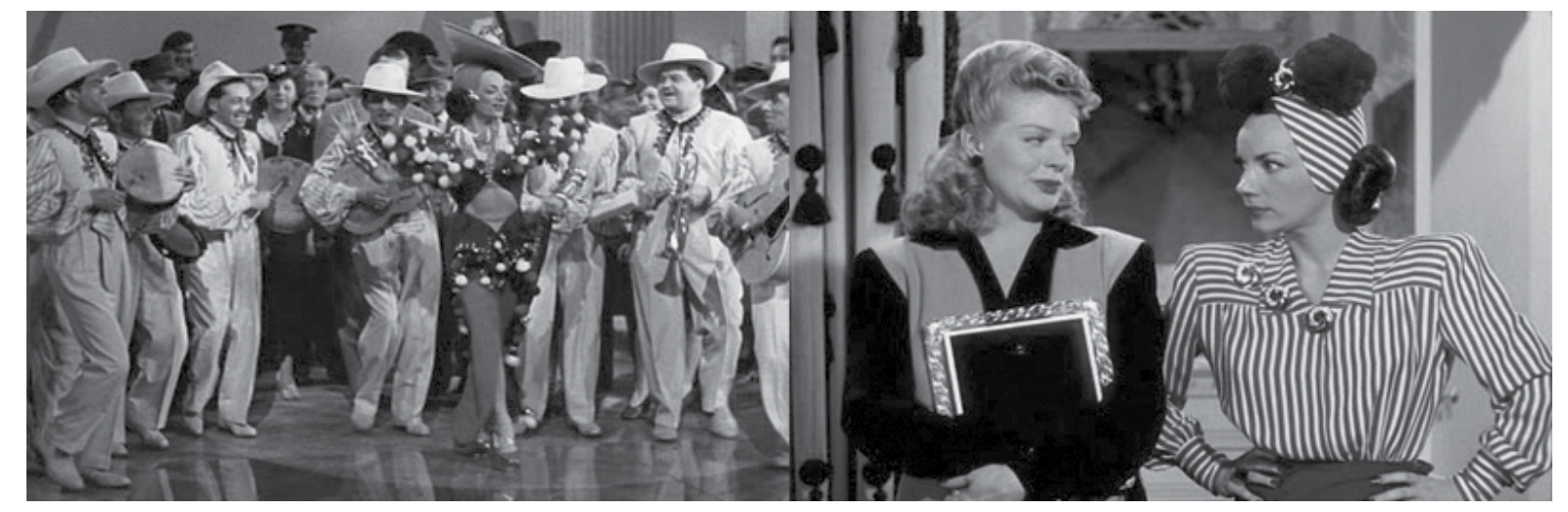

Figura 08-09 - Fotos tiradas do longa-metragem Entre a Loira e a Morena (The Gang'sAllHere). Fonte: Entre a Loira e a Morena. Direção: Busby Berkeley. EUA, 2oth Century Fox, 1943.1 DVD (103 min), color.Comédia Musical. Título original The Gang's AllHere. 


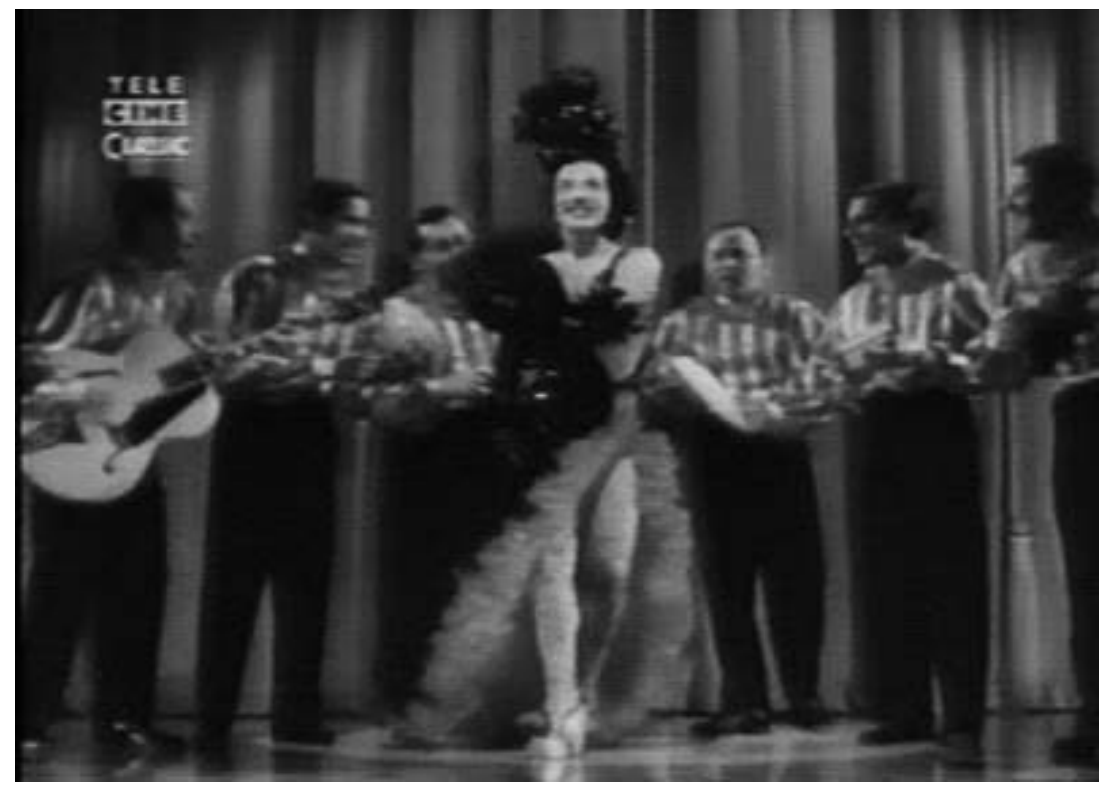

Figura 10 - Foto tirada do longa-metragem Serenata Boêmia (Greenwich Village). Carmen Miranda e o Bando da Lua

Fonte: Serenata Boêmia. Direção: Walter Lang. EUA,2oth Century Fox, 1944.Telecine Classic, 02 de agosto de 2009 as 21:00h. 82 min, color. Comédia Musical. Título original Greenwich Village.

As fotos mostradas acima são do americano Entre a Loira e a Morena (The Gang'sAllHere) dirigido por Busby Berkeley, em 1943, com participação de Carmen Miranda. Como melhor direção e arte (fig.08-09) o filme foi indicado ao Oscar. Carmen Miranda (fig.08) era personagem importante para política de bom relacionamento e a aceitação da comercialização de produtos de outros países no Brasil. O espetáculo foi sucesso naquele período e agradava ao público devido ao número de dança e música que apresentava. Carmen Miranda era a morena brasileira que causava suspiros nos homens. Carmen era engraçada, das roupas às falas, enquanto a americana (fig.o9) era a elegante e requintada que canta na língua inglesa acompanhada pelo batuque do samba. A roupa de Carmen traz a lembrança de que faz parte do seu mundo a nacionalidade americana. As cores da bandeira americana (fig.08) azul, vermelho e branco estão estampadas em sua roupa.

A atriz tem seu rosto com foco mostrado em sequência, várias vezes, ao cantar. Destacam sua presença. Surgem dançarinas que lembram a atriz americana, que faz o papel principal, passando-nos a impressão de que no cenário há várias cópias da atriz americana. No filme há mistura de ritmos e línguas. Parte do intuito também era provocar no espectador associações de ideias na busca de objetos, personagens e música que referenciassem a cultura norte-americana e, ao mesmo tempo, acolhessem outras. 
Esse era o típico estilo de filme musical que agradava a população, passava segurança para os brasileiros, abrindo as portas do país para os EUA e vice-versa. Em 1944, Serenata Boêmia (Greenwich Willage), figura 10 acima, foi produzido por Wlater Lang, filme que americanizou o personagem de Carmen Miranda conforme podemos perceber na figura 64. A meta era a promoção dos EUA, o contexto era de vitória - pela Segunda Guerra Mundial. Detalhes como plumas e pirulitos foram colocados no lugar dos turbantes de frutas característicos da atriz. Um filme animado e com típicas canções americanas. Independente de ser o filme ruim ou bom soube ser persuasivo, cumpriu seu objetivo e trabalhou aspectos culturais tanto latinos quanto norte-americanos.

Ambos os filmes podem passar a impressão de histórias óbvias, ou mesmo fúteis, mas são, na verdade, bem pensados e produzidos. Nesse período de guerra a ideia de filmes musicais foi a melhor opção comercial. O gênero comédia trouxe ao espectador entretenimento e novidade. Afinal, culturas diversas foram apresentadas nesses filmes, independente se estavam corretas ou não, se tinham de fato uma representação próxima ao real, passavam uma mistura de glamour e comédia.

A intenção de conquistar países latino-americanos apresentando suas culturas limitava-se a apresentar os EUA, eles eram o destaque. Também existia uma mescla nos jogos de palavras a fim de buscar atores americanos cantando em inglês em ritmo de música latina ou mesmo dança latina associada à letra da música americana. Eram esses cuidados que envolviam o espectador quanto à vantagem de ser americano ou ser amigo, parceiro dos EUA.

Analisemos, pois, outras ideias de Truffaut (1990). Em 1946 foi filmado Sonhos de Estrela (Doll Face), comédia musical dirigida por Lewis Seiler. Arte do início ao fim, o objetivo da produção era encantar. Alguns filmes produzidos em Hollywood passam a impressão da ingenuidade dos anos $40 \mathrm{e}$ 50, no entanto foram feitos de forma muito inteligente. Exemplos de filmes intelectuais que podem ser considerados ingênuos são Forja de heróis (Air force), O Rio vermelho (Rede River) e O rio da aventura (Big Sky), de Hawks que estava preocupado em agradar ao grande público.

Truffaut considera existir filmes que contribuíram para decadência do cinema, o primeiro: James Bond, O satânicoDr. No foi uma paródia narrativa que o público gostou, porque eram histórias com tradições narrativas que pudessem acreditar. Certa época os filmes eram respeitosos sem liberdade física. Já em o Pimpinela escarlate do ponto de vista sexual é convincente. 
O filme realizado em cores, como A história de Adele $\mathrm{H}$ poderia ter sido em preto e branco, porque a maior parte do longa-metragem é filmado à noite e a tonalidade escura quase faz parte do cenário. Nesse sentido a cor não seria considerada um problema.

Truffaut (1990) entende que para se fazer um filme o prazer deve ser superior ao dever, por isso não se rendia a filmes encomendados. O público precisa querer compartilhar desse prazer; não se deve tentar agradar apenas certo segmento do público.

Variados modos de produção cinematográfica mostram-nos a diversidade artística e tecnológica disponíveis atualmente. Pensando na manipulação, buscamos o estudo de Roxo (2006), que menciona que os EUA souberam usar instrumentos de poder político e econômico, além de conhecimento para internacionalizar seus costumes através do cinema. Da mesma forma os meios de comunicação, de entretenimento e a publicidade de modo geral funcionaram como recursos para popularizar conceitos americanos. As críticas e temores globais são variados porque, querendo ou não, toda produção pode ter valores incutidos implicita ou explicitamente.

Roxo (2006) considera que para fazer cinema ingênuo ou espetáculo intelectual técnica e montagem são determinantes. Talvez pensar na liberdade de se fazer cinema, mostrar suas identidades culturais de forma verídica e alcançar consumo global ao mesmo tempo pareça quase irreal. O cinema, ainda que injusto na apresentação dos dados, é uma forma de catarse. Sendo assim, torna-se uma produção artística que não tem compromisso com o real.

A busca por uma vida melhor para os imigrantes ou a expansão de indústrias americanas contribuiu para uma sociedade multicultural com forte produção de serviços e produtos destinados às massas. Os EUA conseguiram globalizar seus bens de consumo e de serviço. O cinema foi o instrumento de comercialização e interesses políticos. Carmen Miranda foi figura de sucesso que inicialmente era um "produto" de interesse político e demonstração de aceitação dos povos latino-americanos pelos Estados Unidos.

\section{A ARTE DE SE FAZER CINEMA INDUSTRIALIZADO: HOLLYWOOD NA LUTA}

No início da Segunda Guerra Mundial e também no início da Guerra da Coreia, Hollywood pode ser considerada uma história sociocultural de glamour, sonhos, fortuna e beleza. O cinema hollywoodiano é o imaginário, as pes- 
soas vivem no mundo da fantasia. As versões de Hollywood sobre a guerra foram tão importantes quanto ela. As ideias de Otto Friedrich ${ }^{3}$ - anos 40 em Hollywood - contribuíram para lembrar os grandes filmes produzidos pelo império americano, como4: Cidadão Kane, Relíquia macabra, Pacto de sangue e A malvada. Friedrich menciona que com a decadência dos grandes estúdios, quem passou a fazer filmes foram as universidades. Jovens com gravadores na mão entrevistavam sobreviventes de cabelos grisalhos da época de ouro.

Friedrich (1988) assegura que atualmente é utilizada matéria plástica não inflável, ao contrário do que foi para o rosto de "cera" de Ronald Reagan, a perplexidade fica nítida na expressão cordial, além da roupa para colocá-lo de forma monumental. Seu olhar vai além das trevas por trás do seu brasão presidencial. É o museu de cera de Hollywood. Parece que vai além das fronteiras da incoerência interpretar essa escultura de cera.

A "Trust" contra todos os possíveis piratas vivia acumulando processos em Nova York; considera o engenho dos fundadores de Hollywood. Friedrich (1988) afirma que Bertold Brecht anos antes de ter estado em Hollywood havia escrito algo semelhante na abertura de Ascensão e queda da cidade de Mahagonny, algo na imaginação de Brecht em um caminhão danificado que quebrou com três fugitivos da justiça em uma região deserta. Local que resolveram fundar a Mahagonny, ou seja, "cidade das redes". Ele tinha visão de futuro, assim como o conselho administrativo de Hollywood. A justiça de Los Angeles cancela a proibição dos cinemas em 1910, pois não concordava com a restrição dos empreendimentos dos recém-chegados.

O autor ainda comenta que talvez os estúdios também ornassem um cartel ilegal que de um lado ficavam distribuidores e exibidores e de outro, escritores e atores em processo porque não podiam perder. Existiam, em 1939, duas vezes mais cinemas do que hoje, eram 15115 no total. Por ano, uma média de quatrocentos novos filmes era exibida. Em termos de volume, eles eram os responsáveis pela décima quarta indústria e em termos de patrimônio era a décima primeira maior, superando as cadeias de supermercado e máquinas para escritório.

3 Otto Friedrich Müller (1730-1784) nasceu em Copenhagen sendo educado para igreja. Formou-se em Harvard em História. Trabalhou na Stars\&Stripes (Alemanha-Europa) e na Unitede Press (Paris e Londres). (HARPER COLLINS PUBLISHERS, 2012).

4 Cidadão Kane de 1941 por Orson Welles. Relíquia macabra de 1941 por Warner Bros.Pacto de sangue de 1944 por Billy Wilder.A malvada de 1950 por Joseph L. Mankiewicz. Ver: FRIEDRICH (1988). 
Para Friedrich (1988), "criar fantasias enriquecia os criadores. Embora Hollywood não estivesse entre as dez maiores indústrias americanas, colocava-se em segundo lugar na percentagem de vendas e lucros com que premiava seus próprios executivos". (p. 27). Apesar de vários escritores reclamarem, pagavam muito bem. Os contratos curtos eram ainda mais lucrativos. É interessante quando o autor relata que esses senhores da criação ainda lembravam-se do leste da Europa como emigrantes de infância pobre.

Friedrich (1988) explica que Hollywood teve como um dos primeiros refugiados políticos, Arnold Schoenberg. No início eram Mayer, Warner e Cohn. "Tinham sido os pobretões sem ofício", mas, em seguida, fizeram sucesso em Londres e Berlim os diretores, atores e cosmopolitas. Friedrich acha espantoso que não foram criados filmes de oposição ao nazismo com tantos talentos refugiados de Hitler. Considera que o medo fosse uma das razões, além disso, o desemprego e a fome. Hollywood não tinha desejo de se opor ao nazismo. Existiam, em 1936, vários figurões esquerdistas e liberais da Liga Antinazista que foi fundada com intuito de boicotar os produtos alemães. Com o pacto Hitler-Stalin a Liga acabou mudando seu nome para "Liga Hollywood", que apoiava uma política de neutralidade pela Ação Democrática.

Em 1933, por outro lado, o Duce da Columbia Pictures, Harry Cohn, fez um documentário: Mussolini Speaks. Em 1940 o antissemitismo era intenso e estava disseminado na América. Os judeus tinham números de cotas para clubes, corporações e universidades. Eram excluídos dos melhores bairros e da maioria dos cargos executivos. No fundo, Hollywood somente preveniase a qualquer intimidação dos desonestos e estranhos que não agiam contra eles com violência, preconceito que ainda era menor do que com os chineses, mexicanos e negros. O importante para América era o negócio, nada abalou Hollywood, nem mesmo os problemas políticos e as guerras.

Fabricar qualquer coisa era o foco dos grandes estúdios desde que virasse sucesso de bilheteria não importava se era "Dallas ou Indianópolis". "A convocação de uma celebridade para o serviço militar era um grande acontecimento no departamento de publicidade do estúdio e nas revistas para fãs (p.113)". "Assim Hollywood começou a ir à guerra. $O$ exército entrou no novo estúdio de Walt Disney, em Burbank, com um pouco mais do que um 'dá licença' e instalou ali uma bateria de holofotes para proteger a fábrica da Lockheed, vizinha." (p.111). Em Hollywood eram cerca de 2.700 pessoas até outubro de 1942.

Os astros não tinham esforços no intuito de "alimentar canhões", e sim de entreter as tropas fazendo filmes de propagandas e vendendo bônus de 
guerra. Friedrich menciona que HedyLamarr chegou a arrecadar em papéis do governo 17 milhões de dólares em um único dia, apenas oferecendo bônus no valor de 25 mil dólares para homens que os comprassem em troca de seu beijo. Os jovens recrutas queriam combater no Pacífico, gostavam de visitar os pontos turísticos - o principal era Hollywood que gostava de divulgar seu patriotismo - e encontrar outros combatentes para partida em Los Angeles.

São vários os episódios individuais além da Hollywood coletiva que tinha fome de sucesso e dinheiro. Do outro lado, a indústria conquistava a comunidade que buscava tecnologia, estilo e qualidade de vida. Um conjunto de prédios no norte de Los Angeles. Hollywood foi beneficiada pela guerra, trouxe grandes lucros e faturamento para os EUA. Enfrentou problemas como todos que produziam filmes nas décadas de 1940. Os enredos de filmes subitamente ficaram obsoletos. Além disso, o autor afirma que os japoneses ameaçavam o estrelado musical por Eleanor, Parker: J'lltakemanila, nada podia fazer a MGM. A guerra era uma ameaçava ainda maior, pois aumentava seus esforços com as exigências materiais, como a celuloide usada na produção de filmes que passou a ser muito requisitada na produção de explosivos.

Desde 1932 que o serviço secreto do FBI e os agentes militantes vinham investigando a comunidade nipo-americana, já existia grandes volumes de material considerado subversivo, referente ao cidadão do país e também a estrangeiros. "Formadores de opinião", jornalistas e professores eram incluídos na lista de investigação da mesma forma que as lideranças reconhecidas. Aumentava a "pressão para a remoção em massa". Em uma rua de Los Angeles uma nissei foi morta a facadas. Friedrich (1988) ainda afirma que Japoneses eram apedrejados e espancados em incidentes esporádicos.

A confusão não parou por aí, foram vários relatórios publicados a partir de indivíduos como fonte de pressão antinipônica. Porém, apenas lembrando que Hollywood perdia um grande número de seus habitantes. O primeiro campo de redistribuição de japoneses foi em Manzanar em um deserto. Mas, nosso objetivo aqui não é aprofundarmos esse assunto. "Tal como Detroit, Hollywood agora produzia filmes de guerra em série. Por isso, requisitou-se a volta de Ronald Reagan do centro de filmes de treinamento do exército, conhecido como Fort Roach, para estrelar o filme de Irving Berlin: ThisistheArmy (Forja de heróis)." (p.136).

Friedrich (1988) comenta que os pilotos americanos foram homenageados por Hollywood em Air Force (Águias americanas) e DestinationTokyo(Rumo a Tóquio). Da mesma forma que homenagearam as enfermeiras em 
Soproudlywehail (Legião Branca) e marinheiros mercantes em Action in thenorthatlantic (Comboio para leste). Alguns dos filmes produzidos eram realistas, contra as hordas japonesas. Mesmo sem muito realismo os produtores de Hollywood, os mais espertos, sabiam que os filmes de guerra de maior sucesso eram os que mexiam com essas emoções. Havia uma expressão de patriotismo que como outras tantas realidades difíceis a guerra era também simbólica e sem o horror do sangue. Um novo valor à história que profere o grito da guerra. A indústria hollywoodiana enxergava os problemas como certo tipo de solução para si.

Em 1943 iniciaram os tumultos antimexicanos, que eram embaraçosos para Washington já que buscava a Política de Boa Vizinhança com o presidente Roosevelt em relação à América Latina na tentativa de "recrutar os latino-americanos para o combate ainda perigoso contra os Estados fascistas, que muitos sul-americanos consideravam pátrias: a Itália, a Alemanha e, em certa medida, a Espanha." (p.151). A situação também era incômoda para Hollywood, que tentava substituir ou resgatar as vendas perdidas na Europa, mas que vinha, por outro lado, aumentando as vendas na América Latina.

The Ox-Bow incidente (Consciências mortas), filme de 1943, foi o único que trabalhou com seriedade o assunto dos mexicanos. Um romance que trata a respeito de um linchamento sem mencionar a vítima, que era um mexicano. Muitas das figuras que vestiram farda em Hollywood foram lutar; outros, em bom número, dedicaram anos de guerra a fazer filmes. Alguns desses filmes alcançaram considerável distinção mesmo concebida apenas como propaganda.

O exército encontrava entretenimento no cinema. Em 1945, uma das principais produções era fazer o tour dos acompanhamentos militares. Friedrich considera que talvez fosse publicidade de Hollywood pela grande produção de filmes de guerra e seu mais importante cliente eram as forças armadas, quiçá fosse apenas patriotismo. Eram 12 milhões de soldados, um público cativo nessa evolução tradicional do monopólio hollywoodiano, que ficava cada vez mais rico.

Otto Friedrich menciona que Hollywood fazia contratos de sete anos com diretores e pessoas consideradas de valor. Colocando-se como um dos pilares do monopólio. A justificativa era o tempo e o dinheiro gastos ao longo da carreira dos artistas. O estúdio tinha direito às decisões profissionais dos atores. Caso alguém recusasse alguma ordem, tinha o direito de não aceitar, porém seria demitido sem pagamento, indefinidamente ou até que 
concordasse em aceitar o papel que lhe fora destinado e nas condições negociadas pelo estúdio.

Então surge Franckenstein, por James Whale, através da Universal. $O$ cineasta já havia feito o filme Waterloo Bridge (A ponte de Waterloo) por Hollywood. Não foi o realismo de Frankestein que o fez tornar um clássico popular, mas sim a qualidade de uma fábula que conseguiu inocência com "fabuloso exagero". Friedrich (1988) considera que foi um sucesso merecido. Logo após, em Hollywood, surgiu Drácula por Logosi. As imitações nascem e surge, assim, um ciclo de filmes de terror.

No ano de 1935 estreou Bridoffrankestein e, em 1939, SonofFrankestein. Filmes que não foram feitos para serem terríveis, os clássicos eram de terror, estes eram contos de fadas ligeiramente simbólicos. O filme ganhador do prêmio de melhor filme estrangeiro, em 1948, dos Críticos de Cinema de Nova York "não só tratava do nazismo como realmente começou a ser rodado em Roma enquanto o exército alemão ainda estava em processo de evacuação da cidade" (p.362). Roberto Rossellini, em 1944, sem nenhum cenário de estúdio teve de fazer Roma: cidade aberta, usando pedaços de filmes de atores amadores, em sua maioria, do mercado negro. Até então a maior parte de seus trabalhos eram filmes de propaganda. Para os senhores de Hollywood faltavam "valores de produção" em seu filme, o que os deixava indiferentes.

Legiões católicas e guarnições da América Legion(Legião Americana) podiam opinar no comitê da Câmara de investigação do FBI, o que só veio a ocorrer em 1951. Aconteceram várias expulsões, principalmente dos empregados de Hollywood, já que não tinham tanta autoridade. Friedrich (1988) garante que ficou a encargo dos estúdios de Hollywood fazer suas punições, pelos mais variados motivos, como morais, financeiros e políticos. Nos anos de 1940 talvez os filmes tivessem produção barata ou os produtores tivessem pouco retorno financeiro, o que gerava menor investimento em altas produções, sem concorrência.

Agora tratemos do sucesso de Carmen Miranda nos filmes norte-americanos, a partir das ideias de Otto Friedrich. A atriz fez sucesso nos palcos e no cinema nesse período de guerras. Hollywood também utilizou Carmen Miranda na arte de se fazer dinheiro em um período de crescimento da indústria cinematográfica. O Brasil, como toda a América Latina, demorou a fazer seus próprios filmes. Mas, Carmen Miranda virou estrela de Hollywood bem antes disso.

Gatti (2004) afirma que os produtores encantaram-se com o desempenho da atriz. Ela conseguia cantar e interpretar, além de ser coreógrafa e 
figurinista. O filme Alô, alô carnaval, conforme aparece a seguir na figura 13, e a interpretação da música Que é que a baiana tem?,no filme Banana da Terra (fig.14), foram sucesso. Os turbantes e frutas ficaram tão famosos que em seguida veio Entre a loura e a morena (fig.12), uma produção que apresentava toneladas de seus apetrechos que saíam de um navio em uma das cenas na cidade do Recife em Pernambuco no Brasil. Filmes como este tiveram Carmen Miranda em destaque com tempos maiores nas apresentações de algumas das cenas filmadas. Foram realizadas várias divulgações (fig.11-14) dos filmes e comentários da imprensa e público.
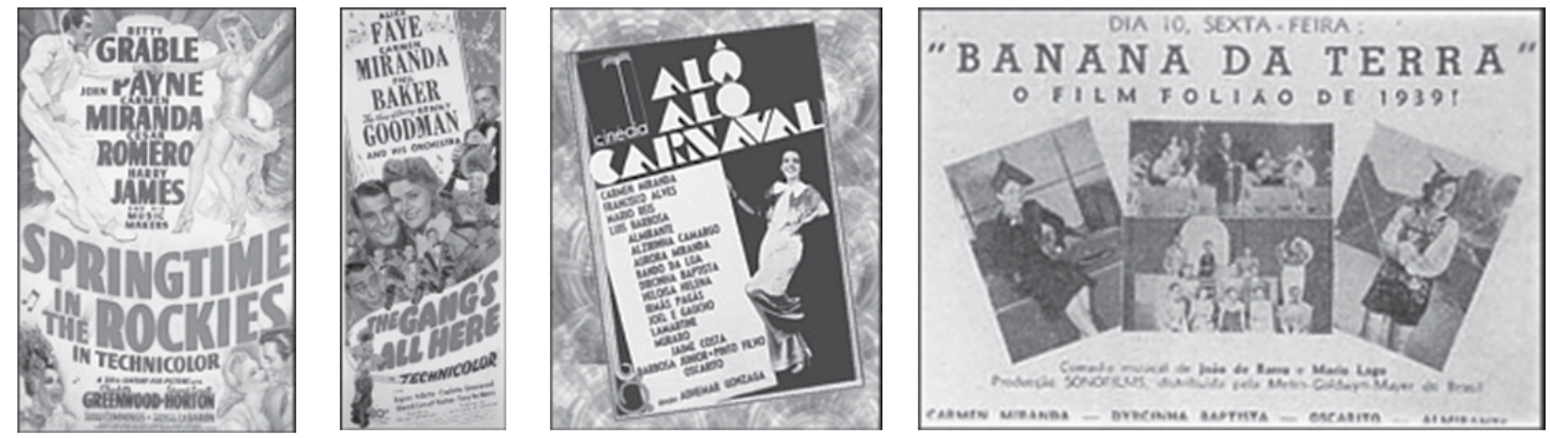

Figuras de 11 a 14- Cartazes de filmes com Carmen Miranda 5

Fonte: Carmen Miranda Homepage (2011).

O Bando da Lua foi o grupo musical de exigência de Carmen Miranda ao ser convidada para trabalhar nos EUA. Dessa forma, seu trabalho foi garantido com qualidade musical já que os americanos não conheciam samba. Nesse momento Hollywood percebeu que era melhor acatar tais exigências já que também seriam favoráveis aos seus interesses. Carmen Miranda, em seu estilo de dança, teve forte presença portuguesa e africana.

Gatti (2004) estudou o gênero musical do bolero hispano-americano e percebeu que teve influência no lirismo do chorinho, que está nas raízes dos anos 40 e 50 do samba-canção brasileiro. Por outro lado, há influência dos desfiles de carnaval do Rio de Janeiro. A letra de Chattanooga choochoo,cantada em português no filme, levanta questões étnicas específicas; a letra altera ritmos de samba para as interpretações dos brasileiros.

Já para o público norte-americano o jazz ultrapassa fronteiras. O filme Minha secretária brasileira (fig.11), usado de exemplo para ilustrar o que es-

5 Fig. 11: Minha secretária brasileira (Springtime in The Rockies), Fig.12: Entre a loura e a morena (The Gang'sAllHere), de 1943. de 1942, Fig. 13: Alô, alô carnaval, de 1936, Fig. 14: Banana da Terra,de 1938. 
tamos falando, é revisto pelo "miscigenado" Bando da Lua, que antes era formado apenas por brancos; nasce uma conexão negra do jazz e do samba, uma representação étnica não branca feita por personagens latino-americanos. Gatti (2004) afirma que o público brasileiro considera Carmen Miranda e os integrantes do Bando da Lua como brancos, o que não os permite enxergar as evidências, assim como a própria ausência afro-brasileira. Mas, mesmo assim, Carmen Miranda teve representação nacional, não existiram apenas questões de relações raciais.

Gatti (2004) assegura que a trajetória da atriz foi infinita para o Brasil e os Estados Unidos, criando sua própria identidade imaginada. O filme Minha secretária Brasileira foi marcado pela presença da atriz e o Bando da Lua representando os não brancos que tinham fala brasileira; mesmo Carmen com suas origens europeias não seria descrita como white. A identidade étnica e cultural faz parte de seus personagens. $O$ filme representa toda uma cultura idealizada, seja pelo real ou imaginário, alguns cineastas criticam e outros são persuadidos pela arte de fazer cinema, que cada vez mais é direcionada aos interesses de comercialização, tendo de deixar em segundo plano a questão estética.

\section{INTERESSES RECÍPROCOS: PERMANECE O COMÉRCIO}

Analisemos os interesses do artista e do contratante quanto à comercialização. Martes (2001) afirma que atualmente são vários os imigrantes que vivem nos EUA, usufruindo do "sonho americano". Os americanos exercem um antigo fascínio sobre a emigração brasileira, não é apenas interesse financeiro, desde a década de 40 que existe certo "jogo de sedução" envolvendo ambos os países (Brasil X EUA).

De acordo com Martes (2001), através dos relatos de pesquisa de Tota, um professor da Pontifície Universidade Católica de São Paulo, em análise de arquivos brasileiros e norte-americanos, pôde verificar que os meios de comunicação foram artifícios bem-sucedidos, lembrando que a política de Boa Vizinhança usou o rádio e o cinema durante o governo Roosevelt. "Sob a ameaça da conquista dos trópicos pelos nazistas, tentou-se atrair a simpatia pelo estilo de vida norte-americana, configurando uma estratégia mais segura e eficaz do que a ameaça aberta de intervenção bélica.” (p.79).

O professor Tora considera o Brasil o país mais frágil em seu processo de americanização. $O$ jogo de atrair os brasileiros pelo estilo moderno de vida 
norte-americano tirou nossos olhares da Europa. Carmen Miranda com suas músicas e nosso café foi elogiada na busca de atrair simpatia pelos EUA. Ainda assegura que a preocupação era colocar seus produtos e valores democráticos na América Latina, sendo de interesse maior pelo Brasil. A OCIAA ${ }^{6}$ foi um plano que promoveu a produção de filmes e cinejornais americanos onde Walt Disney e Carmen Miranda foram os principais responsáveis pela aceitação dos EUA em outros países. Afirma que Carmen tirou a 2oth Century Fox do negativo com seu primeiro filme.

Mitos norte-americanos como o filme Cidadão Kane, de Orson Welles, foram usados por Hollywood para atrair o mercado brasileiro. Martes (2001) afirma que durante a ditadura do Estado Novo a influência americana foi disseminada no Brasil. Os filmes invadiram o país e alavancaram a superioridade industrial americana. Com o apoio da DIP ideias para atrair a simpatia de aliados foram produzidas em grande escala nos EUA e apresentadas através de programas de rádio e divulgadas também para os brasileiros. Martes menciona ainda que o presidente do Brasil, na época Getúlio Vargas, também conseguiu que nossa imagem passasse a ser positiva, o café foi um dos produtos relacionados mundialmente à imagem do país.

O Brasil tinha interesse nos produtos manufaturados dos americanos e os EUA tinham interesse em nossa matéria prima. $O$ autor garante que as propagandas dos noticiários norte-americanos eram realizadas saudando o café brasileiro e solicitando sua aceitação como meio para garantir a união da política de Boa Vizinhança. A mídia era usada pelos americanos com intuito de americanizar o Brasil. Os meios de comunicação e o cinema norte-americano continuavam atraindo cada vez mais o público brasileiro.

A boa recepção que Carmen Miranda teve nos Estados Unidos foi inicialmente pelo interesse de bom relacionamento que os americanos buscavam com outros países, principalmente latino-americanos. Para Martes (2001),

6 OCIAA - Office oftheCoordinatorofInter-AmericanAffairs - foi criada como plano de "sedução" na área de comunicação e informação por Nelson Rockefeller, com ideologias na produção de empatias recíprocas entre Brasil e EUA no processo da Política de Boa Vizinhança desenvolvida pelo governo Roosevelt dos EUA, os meios de comunicação foram os mais usados, particularmente rádio e cinema. O milionário Rockefeller que "capitaneava" essas estratégias achou prudente que americanos fossem tão trabalhados quanto brasileiros, pois os empreendimentos norte-americanos dependiam da simpatia para conseguir sucesso em ambos os países. Fonte: TOTA, Antônio Pedro. O imperialismo sedutor: a americanização do Brasil na época da Segunda Guerra. RAE - Revista de Administração de Empresas/FGV/EAESP, Resenha, v.41, n.2, abr./jun., São Paulo: 2001. 
a talentosa Carmen não esperdiçou a oportunidade e soube fazer fama internacional com seu estilo, levando o samba de suas raízes brasileiras aos palcos e telas estadunidenses.

A música Na batucada da vida foi analisada por Gelamo e Chacon (2006) em duas diferentes interpretações do samba-canção em sua limitação da frase entonacional (conjunto de frases fonológicas). Escolheram Carmen Miranda e Elis Regina ${ }^{8}$ para verificar a interpretação destas figuras no fazer canção dessa música. Puderam comprovar que são diversos efeitos de sentido em cada interpretação e que a frase entonacional de cada intérprete é organizada segundo a percepção de juízes, sendo três indivíduos para cada formação em: linguística, música e fonoaudiologia.

O momento que julgavam existir pausa, concordância inferior a 70\%, era marcado por cada um deles. Surgiram diferentes interpretações de acordo com a entonação. A música envolve toda uma cultura e identidade individual. Os autores afirmam que as interpretes são orientadas por possibilidades de exploração da música de diferentes formas em suas organizações e a reestruturação que vem de natureza linguística. Marcas de subjetividade dessas cantoras foram uma questão de estilo individual. Dessa maneira, independente da época, souberam mostrar suas raízes e individualidades através da voz, ainda que utilizando-se da mesma melodia musical.

Esse "jogo de sedução" e a voz da cantora Carmen Miranda são fatores ainda associados a sua imagem. Notamos que atualmente os meios midiáticos, como sites e pesquisas mesmo estrangeiras, ainda se utilizam da imagem de sucesso da atriz em relações de entretenimento e comercialização de produtos. Tratemos, pois, dos dois casos.

7 Na Batucada da Vida foi uma música composta em 1934 por Ary Barroso e Luis Peixoto. Gelamo Os autores escolheram essas intérpretes por terem gravado a música em épocas distintas. Carmen gravou no ano de 1934 e Elis Regina em 1974. Houve alongamento e silêncio, transcritas melodicamente e harmonicamente, breve tanto nas características acústicas de Carmen Miranda quanto de Elis Regina, obtiveram alta concordância superior a 70\%. In: GELAMO E CHACON (2006)

8 Elis Regina (1945-1982) foi intérprete brasileira e surgiu dos festivais de música nos anos 60. Sua voz e personalidade marcaram presença de palco histriônico. Demonstrava melancolia e alegria ao mesmo tempo nos espetáculos musicais. Grande sucesso de Falso Brilhante e Transversal do Tempo. Adentrou em diversos gêneros musicais, como: MPB, Bossa Nova, Samba e do Rock ao Jazz. Fonte: SILVA, Vinícius R. B.. "O doce \& o amargo do Seco \& Molhados: poesia, estética e política na música popular brasileira”. Dissertação (Mestrado em Letras) Niterói: Universidade Federal Fluminense, 2007. 


\section{kaboodle}

fashion beauty home deals buzz tools trends friends
must see! halloween! fall style $\$ 500$ giveaway

\section{Carmen Miranda}

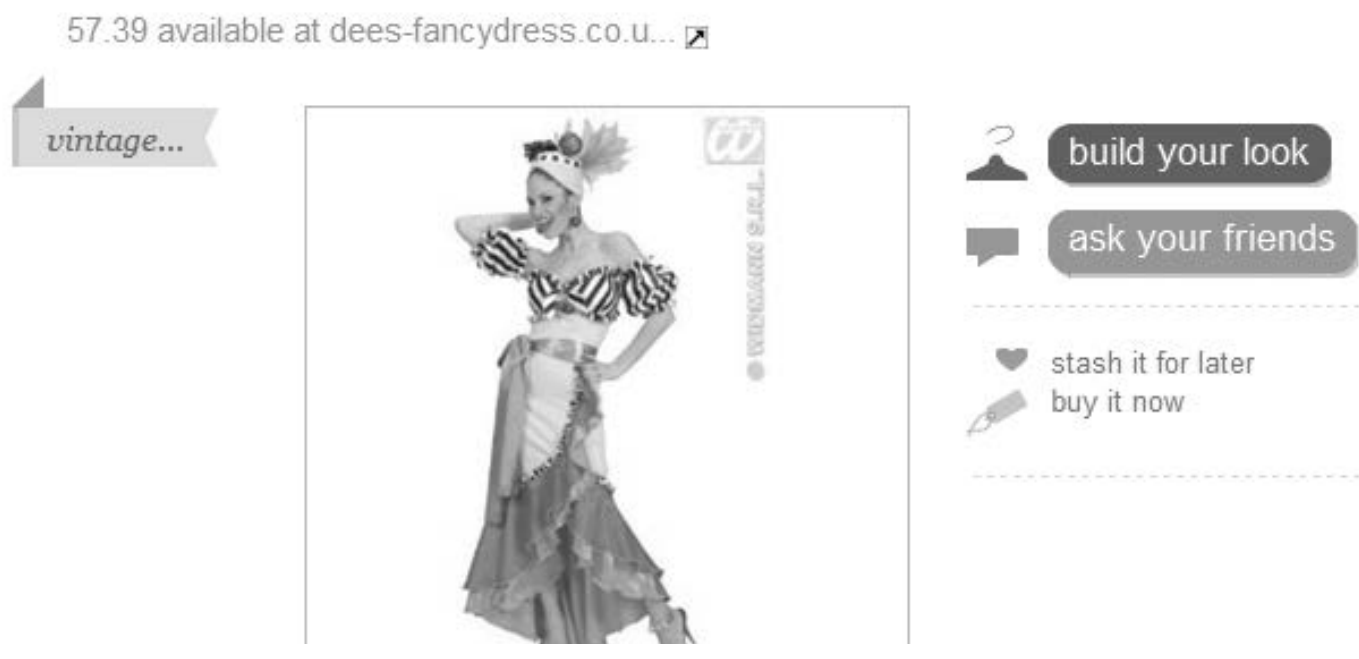

Figura 15 - Foto da página do site Kaboodle

Fonte: Kaboodle (2011).

A página acima da internet da Kaboodle, site de relacionamento e tendências, conforme a imagem acima, tem um espaço de vendas com diversos produtos como roupas de fantasias típicas de diferentes nacionalidades para festas, brincadeiras ou outros tipos de comemorações. $O$ traje de baiana intitulado Carmen Miranda está vinculado à descrição:

MIRANDA Brazilian samba singer and actress most popular in the 1940 s and 1950s. Miranda's enormous, fruit-laden hats are iconic visuals recognized around the world. Often spoofed, Carmen Miranda will always be remembered best for her outrageous outfits and "bowl of fruit" hat. Although she was Brazilian, Carmen was actually born in Portugal. Her family immigrated to Brazil when she was a child. (KABOODLE, 2011)

A roupa é vendida apresentando a atriz Carmen Miranda como forma de vestir do brasileiro. $\mathrm{O}$ traje proporciona todas as lembranças de sua história no cinema. O consumo de artigos ligados à personagem ainda é comum entre a população americana.

No que diz respeito à imagem de Carmen Miranda buscamos também o 
resultado das pesquisas de Balcetis e Dunning ${ }^{9}$ a partir da avaliação social da autoimagem em estimativas de probabilidade estatística. Em seus estudos descobriram que os julgamentos humanos podem ser afetados através da dissonância cognitiva. O intuito foi saber se o sistema de percepção do homem pode ser afetado por ela. Queriam buscar uma forma desconfortável para o sujeito ao medirem a distância. No Estudo 1, alunos da Universidade de Ohio vestiram-se de Carmen Miranda durante um dia e percorreram uma pequena distância a pé (thequadswereactually more 365 feetlong). A roupa usada foi sutiã de coco e um enorme chapéu com frutas e flores. Alguns dos estudantes foram informados que o experimento era para testar a reação quanto a sua vergonha. Outros poderiam escolher entre as roupas de Carmen Miranda ou outras tarefas; todos preferiram vestir a roupa de baiana.

O resultado da pesquisa mostrou que os estudantes que acreditavam estar escolhendo as roupas de Carmen Miranda realizaram a distância em tempo menor do que aqueles que não tiveram opção de escolha. Os pesquisadores Balcetis e Dunning afirmam que essa diferença ocorreu por causa da dissonância cognitiva da falsa percepção da distância. Os indivíduos em condições de alta escolha, presumivelmente para resolver a dissonância, perceberam o ambiente menos aversivo do que os sujeitos que não tiveram escoIha, tendo baixa condição de controle e sendo maior a distância a percorrer.

Os pesquisadores realizaram um segundo experimento, Estudo 2. Neste estudantes tiveram que ajoelhar-se em um skate e subir uma colina. Nessa segunda tarefa mais uma vez o resultado foi o mesmo. Os estudantes que acreditavam ter escolhido, no caso a opção de um ângulo de desenho em uma folha de papel e um transferidor grande com um braço móvel, afetaram menos o seu desempenho do que os que não tiveram escolha da tarefa. Mesmo manipulados, o fato de pensarem que podem decidir algo afeta menos a percepção das propriedades físicas do indivíduo. A inclinação tornouse maior para aqueles que não tiveram percepção visual do ambiente físico a percorrer. A tarefa torna-se fácil ao acreditar que se conhece o trajeto e o modo como será realizado.

Assim, o estudo sugere que o impacto dos estados motivacionais estende de julgamento social para baixo em processos perceptivos. Se buscarmos o site Kaboodle, referente à venda de fantasias de Carmen Miranda, e a

9 BALCETIS, Emily; DUNNING, David. (2007). Cognitivedissonanceandtheperceptionof natural environments. Psychological Science, n. 18, p.917-921, 2007. 
pesquisa de Balcetis e Dunning, referente aos trajes de Carmen Miranda em situação "embaraçosa" no corpo de estudantes modificando suas percepções, podemos notar que Carmen Miranda é uma figura relacionada às lembranças na vida dos americanos tanto quanto na dos brasileiros. Essa percepção da figura baiana - independente do contexto geral ou motivos que usam sua imagem através dessas fontes - nos fez verificar que a atriz é uma figura histórica nos EUA e permanece na avaliação social dessa sociedade.

O cinema foi o responsável por relacionar EUA e Brasil entre os anos de 1940 a 1950. Atualmente, a internet tem o papel de manter esse relacionamento, mesmo após a morte da atriz sua imagem de baiana pode ser resgatada no conhecimento da população. Investimentos e negócios ainda acontecem com o uso de sua imagem, música ou ambos (audiovisual). Sua identidade é um marco na cultura dos EUA.

Tratando da cultura popular, verifiquemos as análises de Roxo (2006). No caso dos Estados Unidos tornaram-se hegemônicos por serem um símbolo com ícones como o fastfood e os meios de comunicação. A música e a cinematografia são identificadas pela população mundial, globalmente existe uma identidade cultural fortemente reconhecível. Carmen Miranda teve sua imagem impulsionada pelos EUA e mesmo com suas raízes americanizou-se adotando as perspectivas internas americanas e em seguida gerando um multiculturalismo em torno de si.

\section{CONSIDERAÇÕES FINAIS:}

Finalizamos compreendendo que são poucas as opções teatrais disponíveis no cinema e notamos, nas ideias de François Truffaut, que existem filmes demais. $O$ cinema está condenado a um mesmo filme, sempre existirão novas versões desses mesmos filmes, ou seja, remake. Apenas espera-se que as novas versões sejam melhores que as originais. Atualmente existem várias versões de filmes que são cópias modernizadas para a comercialização, utilizando a moderna tecnologia e a refilmagem, muitos contam a mesma história inserindo atores famosos e técnicas modernas de filmagem.

A imagem de atores como Carmen Miranda permanece nos arquivos e tem toda uma simbologia que marcou a história de Hollywood, produzindo como fonte de inspiração novas formas de consumo. O público para quem Hollywood produzia os filmes com Carmen Miranda aceitou "compartilhar do mesmo prazer" de quem fazia o filme. Carmen Miranda conseguiu, nesse período em que atuava, levar alegria e desviar o pensamento do sofrimen- 
to de muitas sociedades que viveram em uma época tão tumultuada pelas guerras ou mesmo por buscar desenvolvimento social, cultural e econômico que outros países "pareciam" oferecer. Os EUA viviam um momento de guerra - procuravam distração - e industrialização era o que o Brasil queria.

Carmen Miranda contribuiu para a comercialização de filmes norte-americanos no Brasil. Mesmo que ela pareça uma figura exagerada, sempre está como personagem "ingênuo" e "engraçado". Isto acontecia porque os filmes de Hollywood aproximadamente entre os anos de 1940 a 1950, como foi dito por François Truffaut, preocupavam-se em agradar ao público mostrando sempre um espetáculo com uma mistura de ingenuidade.

Ela virou "estrela" de Hollywood com identidade brasileira e tornou-se uma figura americanizada admirada em todo o mundo. $O$ intuito era associar a felicidade global ao lucro. Discursos individuais em nível global. O individualismo nos filmes passou a ter novos valores que passaram a ser discutidos; as influências culturais foram refletidas como liberdade pessoal; os filmes buscavam modernizar a narrativa usando técnicas para facilitar a aceitação global. Nesse sentido, faziam algo de escala mundial para sobreviver, visionando a busca pela distinção nacional e global. Imagens comuns edificadas em amplitude global passam a ser prioridade nos filmes cujo objetivo é o lucro, uma vez que a alta produção tecnológica torna-se cada vez mais cara.

Os estudos tratados no texto levam-nos a considerar que o filme virou produto de consumo. Foi possível verificar que Carmen Miranda foi alicerce de relacionamento entre países distintos e inseriu no mercado um pouco da identidade brasileira, tornando sua imagem comercializável internacionalmente. O cinema foi o meio de comunicação que melhor soube divulgar a figura de Carmen Miranda e que modificou hábitos no mundo. Independente se os filmes eram "mal" escritos, em sua maioria, tiveram uma boa estética e surpreenderam com o alto número de espectadores nos cinemas.

A figura cinematográfica da atriz modificou o comércio da moda (EUA) e alimentação (Brasil). A produção cinematográfica foi o principal meio que fez da imagem de Carmen Miranda um bem de consumo para as massas. Associada ao dinamismo da vida social dos norte-americanos, a atriz transmitiu determinados valores sem abandonar as raízes brasileiras. Ademais, influenciou o comportamento do público com sua maneira de ser desinibida e engraçada. 


\section{REFERÊNCIAS:}

FRIEDRICH, Otto. A cidade das redes: Hollywood nos anos 40. São Paulo: Companhia das Letras, 1988.

GATTI, José Soares. Carmen Miranda: Tique-taque Transétnico. Revista Universitária do Audiovisual, v. 08, p. 151-166, 2008.

MARTES, A. C. B. O imperialismo sedutor: a americanização do Brasil na época da Segunda Guerra. Revista ERA, v. 41, n. 2, p. 79-80, abr./jun. 2001

ROXO, E. S. E.U.A. e Hollywood: o desejo da projeção Global. Dissertação de mestrado em Estudos Americanos. Universidade Aberta, Lisboa, 2006.

TRUFFAUT, François. O cinema segundo François Truffaut. Textos reunidos por Anne Gillain; tradução de Dau Bastos. Rio de Janeiro: Nova Fronteira, 1990.

. Os filmes de minha vida. Rio de Janeiro: Nova Fronteira, 1989.

\section{Eliane Meire Soares Raslan}

Doutoranda em Comunicação Social pela PUCRS. Pesquisadora, orientadora e professora da UEMG. 